\title{
INTEGRATED EVALUATION OF COST, SCHEDULE AND EMISSION PERFORMANCE ON ROCK-FILLED CONCRETE DAM CONSTRUCTION OPERATION USING DISCRETE EVENT SIMULATION
}

\author{
Chunna Liu
}

State Key Laboratory of

Hydro Science and Engineering

University of Tsinghua

Beijing, 100084, CHINA

Changbum R. Ahn

Charles Durham School of Architectural

Engineering and Construction

University of Nebraska-Lincoln

Lincoln, NE 68588, USA
Xuehui An

State Key Laboratory of

Hydro Science and Engineering

University of Tsinghua

Beijing, 100084, CHINA

SangHyun Lee

Department of Civil and

Environmental Engineering

University of Michigan

Ann Arbor, MI 48109, USA

\begin{abstract}
Massive concrete dam projects will be conducted in the next ten years to respond to the increasing demand for clean energy and water resources in developing countries. With more attention paid to environmental issues, there is an increasing need to develop a methodology for reliably predicting the integrated performance of cost, schedule and emission factors in the planning stage. In this paper, we propose a methodology for using discrete event simulation (DES) for dam construction processes to enhance the performance dynamically. A case study is conducted to demonstrate the effectiveness of the DES model, which is validated by the actual cumulative progress on the construction site. The results indicate that the cost, schedule and emission performance are highly interactively correlated when using RFC in dam projects. The promoted methodology could help construction managers compare the integrated performance of different options in RFC dam constructions.
\end{abstract}

\section{INTRODUCTION}

Taking into account the population increase and climate change in developing countries, dams constructed for a specific purpose or multipurpose - such as irrigation, production of electricity, water supply, flood control, navigation, water quality, or sediment control - will be important to the keep up the rapid economic development in these countries (International commission on large dams (ICOLD), 2012). According to the statistical data, the potential need for concrete dams will be more than double the volume of the existing dams in the next 20 years (Lempérière, 2006). Therefore, a significant number of dams will be constructed.

It is predicted that the volume of concrete in constructing dams could reach more than 1 billion cubic meters - a number rendered by summing the volume of existing concrete dams registered in ICOLD. More than 400 million $\mathrm{tCO}_{2}$ eq would be generated, along with the potential demand of increasing dam projects to be constructed in these countries in the future. The EPA (2008) also pointed out that in the U.S., GHG emissions from construction operations represent $1.7 \%$ of the total emissions. Although these 
emission impacts become significant, they are underestimated. Cost and schedule performance are still the only factors considered when selecting dam construction operations (Kuehn, 2011). Moreover, cost performance has an impact on emission performance during construction processes (Carmichael et al. 2012) and the change of the project's duration would influence the evaluation results on emissions (Tang et al. 2011). The schedule performance closely relates to the cost and environmental performance as well (Ahn and Lee 2013).

With the growing attention paid to reducing the potential emissions when developing dam projects, it is necessary to evaluate not only the cost and schedule performance, but also the emission impacts of different operations in dam projects. Regarding the conventional dam construction method, enough historical data on previous projects supports evaluating performance according to these three factors. However, as to an innovative method-Rock-Filled Concrete (RFC) proposed by Jin and An (2003) - there is a lack of historical data to do such evaluations. RFC combines self-compacting concrete (SCC) and large chunks of rocks, reducing the proportion of cement in concrete and cutting down the emissions.

Due to its better cost and schedule performance than common dam construction method, since 2005, RFC has been widely used in many concrete dams in China (Jin et al. 2005, Huang et al. 2008). To coincide with the rapid implementation of RFC, there is an increasing need to develop a methodology that reliably predicts the integrated performance of cost, schedule and emission factors in the planning stage. This methodology would be beneficial for evaluating the potential influence of different construction options, thereby supporting decision-makers in selecting more-effective construction operations.

To foster better-informed decisions and to promote the development of new construction methods for dam projects, our objectives in this paper are to 1) develop a methodology for using discrete event simulation (DES) to assess the integrated performance of the cost, schedule and emissions for RFC, and to 2) enable construction managers to consider the impacts of their decisions on these three factors. This paper begins by simply introducing the mechanism and application of RFC. Then, by reviewing the previous studies about the cost, schedule and emission performance of construction operations as well as the application of the discrete event simulation (DES) model in the evaluation system, we develop a methodology for using DES to reveal the integrated performance of the three factors (i.e. cost, schedule and emission) in the methodology section. Then a RFC dam project is analyzed as a case study to demonstrate that the presented methodology could evaluate the integrated performance of construction operations. The results show the impacts that different decisions have on the integrated performance of a dam project. Further discussions are made to reveal the relationship of these three factors.

\subsection{The use of Rock-filled Concrete}

The rock chunks in RFC visibly achieve a high filling rate since SCC has the advantages of fluidity and compactness, and depends on its own self-gravity to fill all of the voids in a rock-block mass without the use of vibration (Jin and An 2003; An et al. 2005). Regarding the specific characteristics of RFC, the construction processes are different from those of conventional concrete. First, some quarried rocks with the grain-size of greater than $30 \mathrm{~cm}$ are transported to the construction site and are well cleaned. After excavators level the rock-chunks in the working space, SCC is either pumped into the working space or poured directly on to the surface of rock-block mass. The SCC then flows down to fill all the spaces by merit of its own weight, good fluidity, and high segregation resistance. Some researchers have pointed out that applying RFC can significantly simplify construction procedures by eliminating the surface roughening and vibrating concrete processes, resulting in the continuous pouring of SCC and faster construction (An et al. 2005; Huang et al. 2008).

Since there are rarely studies about the construction processes that use RFC, it is difficult to obtain the interactions among cost, emission and schedule factors, a fact that prevents managers from making informed decisions regarding operation processes. Therefore, with the increasing application of RFC in construction sites, we need to develop an appropriate methodology for objectively evaluating the integrated performance of different operations that use RFC - especially the relationship between cost, emissions, 
and schedule factors - and thereby provide a more comprehensive picture of RFC's strengths and weaknesses to decision-makers.

\section{PREVIOUS RESEARCH}

Emissions from construction operations have not been given sufficient attention until recently, as it was believed that construction operation emissions were less important than those coming from operating the building over its lifetime (Hendrickson et al. 2000; Sharrard 2007). However, as the pressure of climate change-related risks mounts, a significant cut in carbon emissions from construction operations will become a top priority if construction firms are required to meet increasingly stringent emission controls (Wong et al. 2012). LCA is recognized as a regular methodology to analyze the emission performance during construction processes (Bilec et al. 2007). However, there are some deficiencies in applying LCA methods to a construction operation. Construction processes are characterized by several subsequent, parallel, and conflicting processes that change the schedule of different alternatives. LCA is based on static calculation procedures of environmental and cost performance separately, and is therefore unable to consider dynamic interrelationships during construction processes (Löfgren B. and Tillman A. 2011). The results analyzed by LCA are deterministic since the estimates represent the average- and fixed-parameters (e.g. the process duration, productivity) that exist in a construction site. Since RFC is an innovative technology applied extensively in China in recent years, there is not enough historical data to present an accurate evaluation using the above methods. Due to the large-scale characteristic of dam projects, it is also impossible to implement experiments on a construction site to test the performance of different operations using RFC. Thus we cannot simply use available data to conduct an LCA approach to dynamically evaluate the operation options during a construction process.

Construction simulation is the science of developing and experimenting using representations of construction systems in order to understand the behavior in the operation. The simulation models represent the construction processes, and as such can be used to develop appropriate plans, minimize costs or project duration, and improve overall construction project management (AbouRizk 2010). In models, the control actions that contractors can alter are modeled and compared (Ioannou and Martinez 1996), and the integrated performance of the cost, schedule and emission factors are shown respectively.

Discrete event simulation (DES) has been successfully applied to modeling construction operations since the first construction simulation tool-CYCLONE - was introduced by Halpin (1977). Many other simulation tools were later developed to model various construction operations, such as STROBOSCOPE (Martinez and Ioannou 1994), ETZStrobe (Martínez 2001), Simphony (AbouRizk and Hajjar 1998), and so on. In the DES model, construction managers can experiment with multiple scenarios in order to realize the goal of a low-cost, a low-pressure environment, or a minimum project duration (Martinez 2010). DES is more practical and has the advantage over on-site experiments because it does not sacrifice much cost or time.

With regard to the emission performance, Ahn and Lee (2013) applied the DES method to predict the environmental performance of construction operations by changing the operations' efficiency. González and Echaveguren (2012) integrated the DES method into a research framework to study the incorporation of environmental goals in the design of a road construction operation. The DES approach is considered a primary means of simulation because it focuses on construction operations to state variables' changes and to reveal the integrated performance instantaneously at separate points in time.

Existing research mainly focuses on optimizing for either cost, schedule or emissions, and comparatively less attention has been placed on a more holistic estimation of the integrated performance embracing all three factors during construction processes. The DES approach has been applied to reveal the environmental performance of construction activities; however, for this new construction method, its application to emission, cost and schedule performance has not been fully explored (Wong et al. 2012). Decision-makers mainly consider the operating costs and schedule in their planning stage, which does not guarantee an emission reduction. González and Echaveguren (2012) pointed out that further research 
should consider comprehensive analysis involving cost, time, and emission levels. There remains a need for a method to evaluate the integrated performance of RFC with regards to cost, schedule, and emissions.

\section{METHODOLOGY}

This study established a methodology for using DES to estimate the integrated performance of dam construction operation when using RFC. The framework is described in Figure 1.

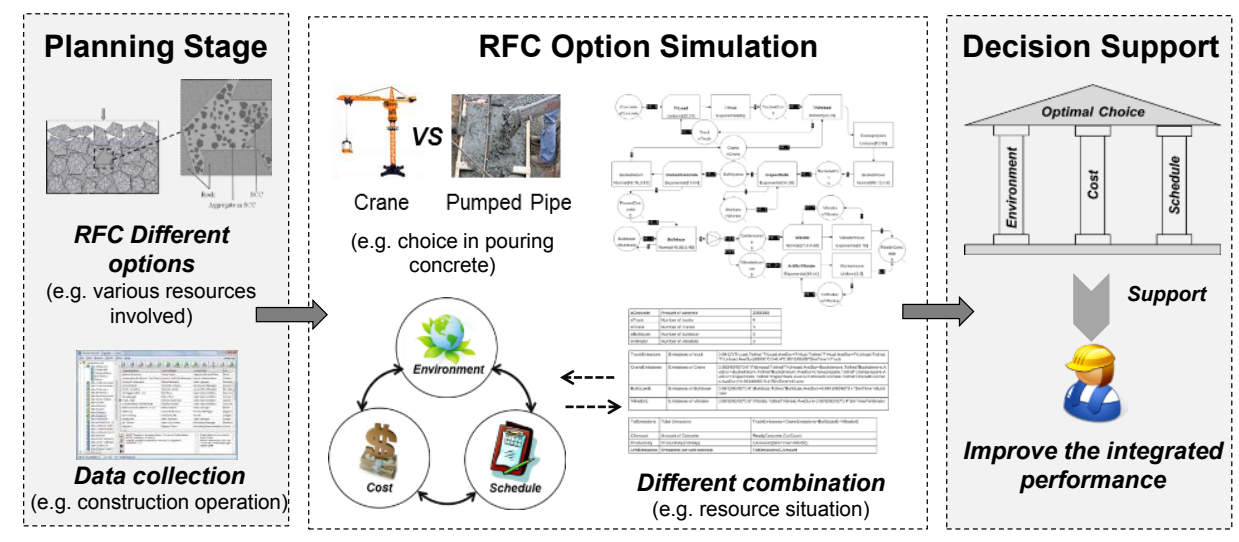

Figure 1. Research framework

In the planning stage, there are different options for RFC construction methods that involve various resources. Through data collection, we gathered on-site and designed data for the whole construction process. Then, we explored a simulation model based on a DES concept that focuses on equipment usage during the operation stage. In this study, we focused on the fuel and electricity-intensive heavy equipment-excavators, cranes, concrete pumps, bulldozers, etc.- used in different types of RFC projects. These pieces of equipment consume a large portion of total operation cost, and are expected to produce a significant amount of carbon emissions during their operation and idling. Using videos of construction sites, we statistically generated estimates for equipment-operating hours and used the resulting information in the simulation model to simultaneously assess the integrated performance of cost, schedule and emissions within the process parameters. In this way, we obtained the integrated performance of the three factors for the different dynamic operation options. This methodology offers a comprehensive solution that will help decision-makers form a better understanding of the construction operation and explore the relationships among cost, schedule, and emissions while selecting the most appropriate integrated performance from among several proposed construction operations.

\section{CASE STUDY}

\subsection{Case Simulation}

A dam project in the Shanxi Province in China was applied for the case study. The volume of the new concrete dam body amounted to $40,698 \mathrm{~m}^{3}$ and the filling rate of rock chunks in RFC could achieve $62.4 \%$. In this case, cranes were applied to transport rocks onto the dam. We obtained the operation sequence and the operating time of different activities by on-site videos. Then we established the DES model using ETZStrobe platform. ETZStrobe is based on activity cycle diagrams and employs the three-phase activity scanning paradigm. It is therefore naturally adept for complex systems where many resources collaborate to carry out tasks typical in construction (Martínez 2010). The simulation model consists of a series of activities that include different pieces of equipment, and the distribution of the duration of each activity is summarized in Table 1. 
Table 1: The estimated duration of equipment operation in the Case Study

\begin{tabular}{|l|l|l|}
\hline \multicolumn{1}{|c|}{ Equipment } & Operation & \multicolumn{1}{c|}{ Distribution } \\
\hline \multirow{4}{*}{ Mixer } & Load & Uniform [26,7] \\
\cline { 2 - 3 } & Haul & Exponential[1200] \\
\cline { 2 - 3 } & Unload & Uniform[30,3] \\
\cline { 2 - 3 } Truck & Back & Exponential[1200] \\
\hline \multirow{4}{*}{ Crane } & Load & Uniform [45,7] \\
\cline { 2 - 3 } & Haul & Exponential[1800] \\
\cline { 2 - 3 } & Unload & Uniform[50,3] \\
\cline { 2 - 3 } & Back & Exponential[1800] \\
\hline Excavator & Move & Normal[300,10] \\
\cline { 2 - 3 } & Unload & Uniform[50,3] \\
\cline { 2 - 3 } & Back & Normal[300,10] \\
\hline Pumper & Pile Rock & Normal[55,3.6] \\
\hline
\end{tabular}

In the table, the estimated duration of each operation is obtained by the on-site video. Each activity is recorded more than 25 times. Then we applied the StatFit Version 2 to get the distribution above. In this case, the established simulation model is showed in Figure 2.

On-site equipment (mixers, cranes, trucks and excavators) were represented as the resources in the model, and the activity of each item of equipment (loading, unloading, hauling, moving, moving back, pumping and piling rocks) were described as the tasks. After being mixed, the concrete was pumped to the construction site, where rocks had been transported by cranes and piled by excavators. In order to validate the model, we ran the simulation model 100 times and obtained the predicted schedule performance and accumulated progress in the construction period. The schedule performance is defined as the volume of the concrete poured per day, which can be seen in the Equation (1):

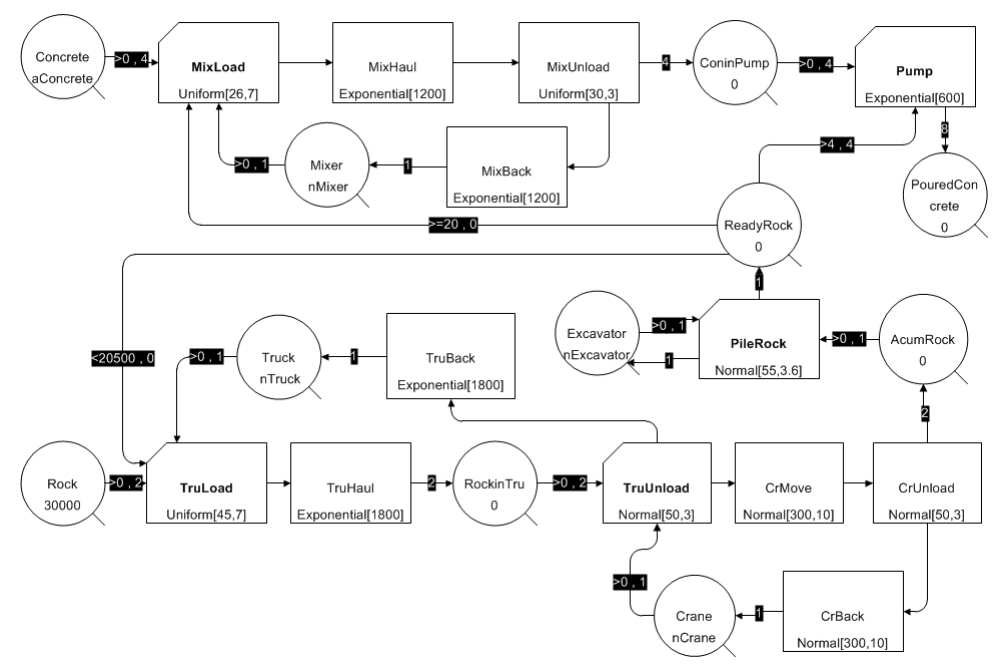

Figure 2. The simulation model of the Case Study

$$
S_{\text {performance }}=\frac{V_{\text {concrete }}}{D_{\text {total }}}=\frac{V_{\text {concrete }}}{T / 60 / 60 / H_{\text {value }}}
$$


where the $\mathrm{V}_{\text {concrete }}$ means the volume of the concrete poured, $\mathrm{S}_{\text {performance }}$ is the schedule performance, $\mathrm{D}_{\text {total }}$ represents the number of operation days, $\mathrm{T}$ is the total operation time, and $\mathrm{H}_{\text {value }}$ means the valuable working hours per day. Then the results were compared with the actual schedule performance observed on the construction site, which are shown in Figure 3.

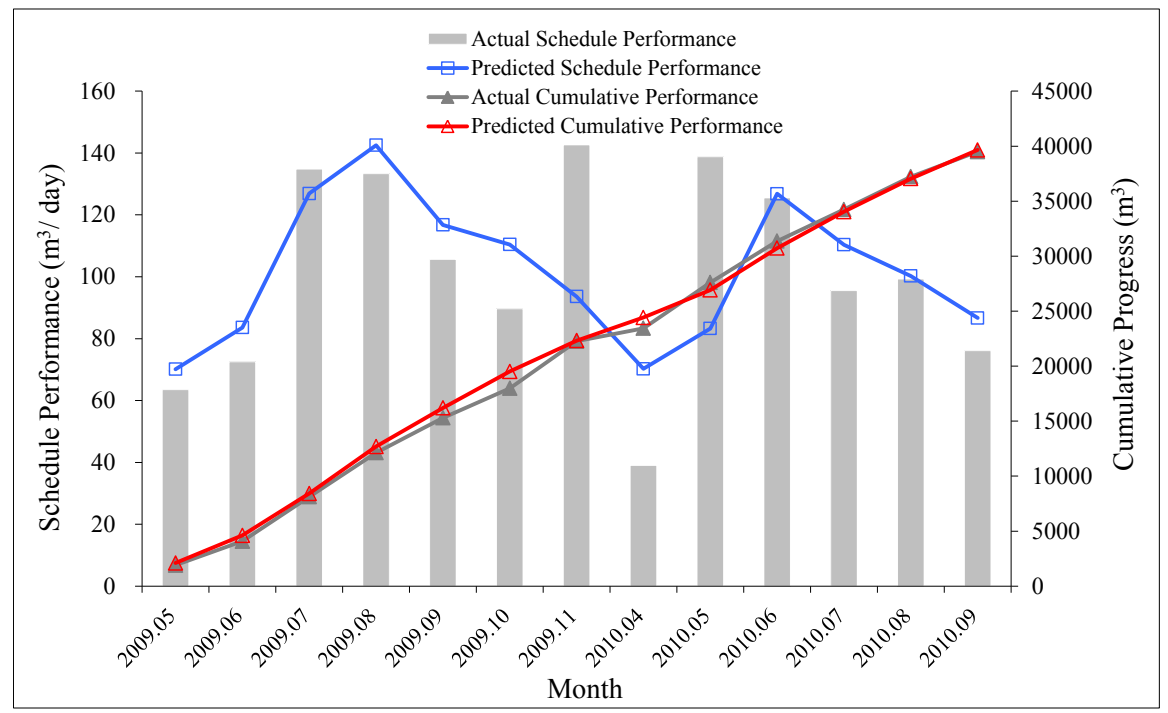

Figure 3. The validation of the established simulation model

It is seen that the predicted schedule performance from the simulation model showed that when the climate was warm, there was a higher schedule performance, since warm weather facilitates the curing of concrete and more daylight extends working hours. In the actual construction progress, though, there were some differences from the predicted schedule performance. According to the on-site record in November 2009 and May 2010, the amount of poured concrete reached about $140 \mathrm{~m}^{3} / \mathrm{day}, 50 \%$ more than the planned performance. This was because the amount of working hours per day was more than those expected in the planning stage - which had budgeted to include catch-up time that proved unnecessary. Regarding the schedule performance in April 2010, the value of the schedule performance was less than 40 $\mathrm{m}^{3} /$ day, while the predicted value was $70 \mathrm{~m}^{3} /$ day. The decline in performance compared to preceding months had been predicted in the simulation model due to expected unskillful operation at the beginning of the restarted project; the difference between the predicted and actual value was mainly caused by a delayed restart. With time moving on and the operation becoming more skillful, the schedule performance improved. The results show that the predicted cumulative progress from the simulation model was reasonably almost consistent with the actual one. In September 2010, the assignment of pouring approximately $40,000 \mathrm{~m}^{3}$ concrete had been completed as the schedule designed. Thus, the established DES model can be used to evaluate the integrated performance of cost, schedule and emission factors.

\subsection{Results}

According to previous studies, we know that the operational efficiency that indicates the efficient use of resources is one of the most important factors for determining the environmental performance of construction operations. Moreover, the environmental performance is also influenced by cost and schedule performance. In this case, the number of cranes, concrete mixers and trucks are designed to be 1, 2 and 6 , respectively. In order to analyze the cost, schedule and emission performance in the different construction operations using RFC, here we changed the equipment fleet in order to alter the operation efficiency. The amount of cranes is therefore kept at 1 while the number of mixers and trucks are changed to different 
combinations - without considering the external limitations of the construction site. The cost performance calculated could be formulated as:

$$
C_{\text {performance }}=\frac{V_{\text {concrete }}}{C_{\text {total }}}=\frac{V_{\text {concrete }}}{C_{\text {direct }}+C_{\text {indirect }}}
$$

where $\mathrm{C}_{\text {total }}$ is the total cost of on-site equipment - calculated by adding the direct and indirect cost. $\mathrm{V}_{\text {con- }}$ crete means the volume of the concrete poured.

Regarding the emission performance, it is formulated as:

$$
\begin{gathered}
E_{\text {performance }}=\frac{V_{\text {concrete }}}{\sum_{i=\text { equipment }} T \times\left(\alpha \times E F_{\text {working }}+(1-\alpha) \times E F_{\text {idling }}\right)} \\
E F_{\text {working }}=\sum C_{e} * E F_{\text {electricity }}+C_{o} * E F_{\text {oil }} \\
E F_{\text {idling }}=\beta * E F_{\text {working }}
\end{gathered}
$$

where $\mathrm{V}_{\text {concrete }}$ and $\mathrm{T}$ are the same as those in the Equation (1). $\alpha$ represents the working rate of each piece of equipment, which is provided by the developed DES model including the overall logic of works and various resources in accordance with each operation plan. $\mathrm{EF}_{\text {working }}$ is defined as the emission factor for the working modes and $\mathrm{EF}_{\text {idling }}$ is the emission factor for the idling modes. $\mathrm{C}_{\mathrm{e}}$ and $\mathrm{C}_{\mathrm{o}}$ are the estimated fuel and electricity consumption for each equipment item per hour, respectively, when the equipment is working, which can be looked up in the Hydraulic Construction Mechanical Quota (2004). $\mathrm{EF}_{\text {electricity }}$ is the emission factor of local electricity in the Chinese Reference Life Cycle Database (CLCD) (Liu et al. 2010) and $\mathrm{EF}_{\mathrm{oi}}$ is the emission coefficient for diesels, which is from BP China (2010). Based on the study presented by Lewis et al. (2010), $\beta$ is calculated for each equipment on site using the generalized ratio of idle-to-non-idle fuel-use rates, as well as the ratio of idle-to-non-idle $\mathrm{CO}_{2}$ emission rates, which are generally between 0.2 and 0.3 (Ahn and Lee 2013). The comparison results are shown in Figure 4.

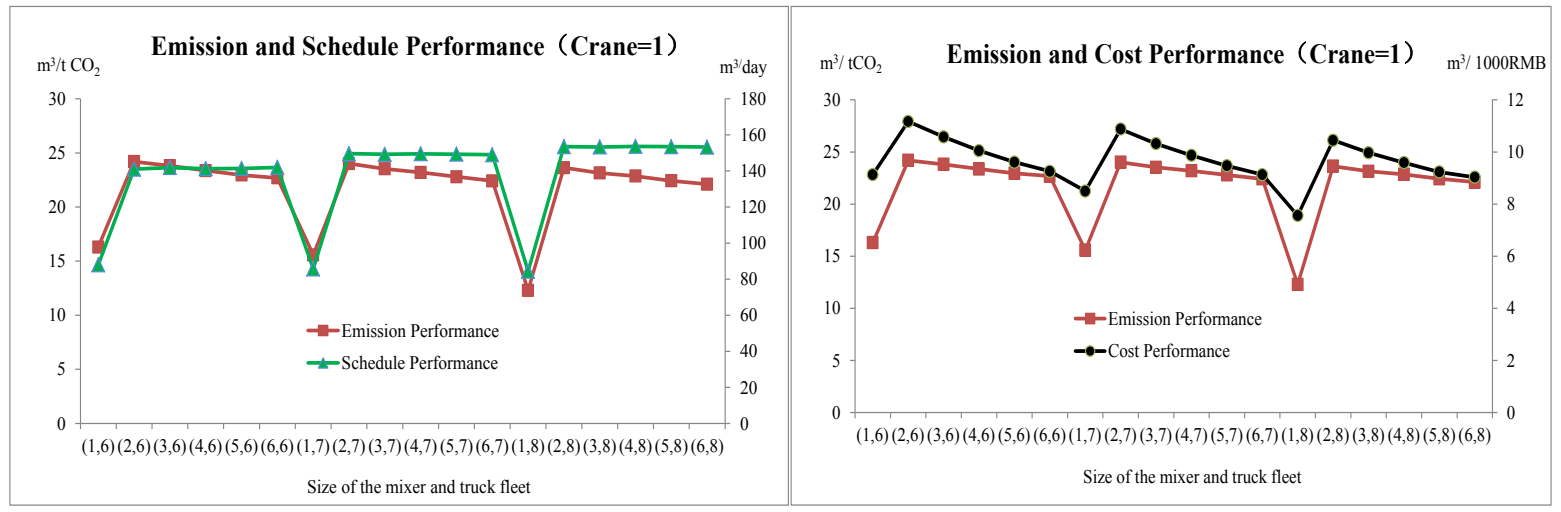

Figure 4. Cost, schedule and emission performance of the alternative mixer- and truck-fleet sizes

It is seen that while increasing the size of the concrete mixer- and truck-fleets yields no obvious improvement in the emission and cost performance, the schedule performance is expedited significantly. When the size of a truck fleet rises to 8 , the schedule performance achieves about $153 \mathrm{~m}^{3} /$ day, though the emission and cost performance still keeps at $24 \mathrm{~m}^{3} /$ ton $\mathrm{CO}_{2}$ and $11 \mathrm{~m}^{3} / 1000$ Yuan, separately. Moreover, when the number of trucks is fixed and the number of mixers increases (except when the number of mixers is 1), the cost and emission performance decreases while the schedule performance grows. This result is due to the fact that though the average operation efficiency of the equipment is brought down, the schedule performance is enhanced by the increasing amount of equipment. Regarding the situation where 
the number of mixers equals 1: though the number of trucks increases from 6 to 7 or 8 , there is no alteration in the schedule performance, but the cost and emission performance decreases due to the low operation efficiency of trucks and high operation efficiency of mixers. Thus it can be concluded that when operation efficiency changes, the better cost or emission performance does not always guarantee the better schedule performance. Sometimes the schedule performance cannot reach its optimum value due to the limitations of equipment. That said, we can still obtain an improved cost or emission performance and get an appropriately integrated performance.

\section{DISCUSSION}

In the case study, the DES methodology effectively evaluates the cost, schedule and emission performance of different operations using RFC in dam construction since the established model can dynamically reflect construction processes. When we change the operation efficiency of the equipment, it can be seen that though some alternatives improve the schedule performance obviously, their corresponding emissions and cost performance may decrease. This result can be explained by the fact that increasing the number of mixers and trucks accelerates the operation efficiency of the crane but leads to more cost. Though the total operating time is shortened, the cost performance is still not improved.

As to emission performance, valuable operating time for each type of equipment is a fixed value when there is a designed working load. The changeable value is the non-valuable operation time - in other words, the idling time (Ahn and Lee 2013). Reducing the idle time of construction equipment onsite not only helps reduce the fuel use and construction-related emissions, but also helps extend the life of the engines and provides a safer working environment for operators and workers on site (Heydarian et al, 2011, Zou et al, 2007, Wong et al. 2012). Since the idling time is improved in the examined alternatives, the emission performance is reduced. Crane is a piece of significant equipment on construction site. The number of cranes used on construction site will determine the operation efficiency and the idling time of cranes, which will influence the integrated performance a lot.

In order to analyze the interactions among cost, schedule and emission performance, we further evaluate the corresponding coefficients when changing the number of cranes used on construction site. Following the analysis processes above, we examined other scenarios created by changing the number of cranes to 0 and 2. Thus the values of cost, schedule and emission performance of different construction operations could be obtained for each scenario. In each scenario, there are eighteen types of operations, which can be used as eighteen variations for analyzing the relationship among the cost, schedule and emission performance. We applied SPSS 16.0 to calculate the corresponding coefficients among the three factors in different scenarios (i.e. the number of cranes is $0,1,2$ ). The results are shown in Table 2, Table 3 and Table 4, respectively.

Table 2. The relationship among cost, schedule and emission when the number of cranes is 0 .

\begin{tabular}{|l|l|l|l|l|}
\hline & & Emission & \multicolumn{1}{|c|}{ Cost } & Schedule \\
\hline \multirow{4}{*}{ Emission } & Pearson Correlation & 1 & $.851^{* *}$ & $.869^{* *}$ \\
\cline { 2 - 5 } & Sig. (2-tailed) & & .000 & .000 \\
\cline { 2 - 5 } & $\mathrm{N}$ & 18 & 18 & 18 \\
\hline \multirow{4}{*}{ Sost } & Pearson Correlation & $.851^{* *}$ & 1 & $.688^{*}$ \\
\cline { 2 - 5 } & Sig. (2-tailed) & .000 & & .005 \\
\cline { 2 - 5 } & $\mathrm{N}$ & 18 & 18 & 18 \\
\hline \multirow{4}{*}{$\begin{array}{l}* \text { Schedule } \\
\text { Correlation is significant at the } 0.01 \text { level (2-tailed). }\end{array}$} & Pearson Correlation & $.869^{* *}$ & $.688^{* *}$ & 1 \\
\cline { 2 - 5 } & Sig. (2-tailed) & .000 & .005 & \\
\cline { 2 - 5 } & $\mathrm{N}$ & 18 & 18 \\
\hline
\end{tabular}


Table 3. The relationship among cost, schedule and emission when the number of cranes is 1.

\begin{tabular}{|l|l|l|l|l|}
\hline & & Emission & Cost & Schedule \\
\hline \multirow{4}{*}{ Emission } & Pearson Correlation & 1 & $.813^{* *}$ & $.936^{* *}$ \\
\cline { 2 - 5 } & Sig. (2-tailed) & & .000 & .000 \\
\cline { 2 - 5 } & $\mathrm{N}$ & 18 & 18 & 18 \\
\hline \multirow{4}{*}{ Sost } & Pearson Correlation & $.813^{* *}$ & 1 & $.616^{*}$ \\
\cline { 2 - 5 } & Sig. (2-tailed) & .000 & & .006 \\
\cline { 2 - 5 } & $\mathrm{N}$ & 18 & 18 & 18 \\
\hline \multirow{4}{*}{ Schedule } & Pearson Correlation & $.936^{* *}$ & $.616^{* *}$ & 1 \\
\cline { 2 - 5 } & Sig. (2-tailed) & .000 & .006 & \\
\cline { 2 - 5 } & $\mathrm{N}$ & 18 & 18 & 18 \\
\hline & Correlation is significant at the 0.01 level (2-tailed). \\
Correlation is significant at the 0.05 level (2-tailed).
\end{tabular}

Table 4. The relationship among cost, schedule and emission when the number of cranes is 2 .

\begin{tabular}{|l|l|l|l|l|}
\hline & & Emission & \multicolumn{1}{|c|}{ Cost } & Schedule \\
\hline \multirow{4}{*}{ Emission } & Pearson Correlation & 1 & $.922^{* *}$ & $.947^{* *}$ \\
\cline { 2 - 5 } & Sig. (2-tailed) & & .000 & .000 \\
\cline { 2 - 5 } & $\mathrm{N}$ & 18 & 18 & 18 \\
\hline \multirow{3}{*}{ Sost } & Pearson Correlation & $.922^{* *}$ & 1 & $.883^{* *}$ \\
\cline { 2 - 5 } & Sig. (2-tailed) & .000 & & .006 \\
\cline { 2 - 5 } & $\mathrm{N}$ & 18 & 18 & 18 \\
\hline \multirow{3}{*}{ Schedule } & Pearson Correlation & $.947^{* *}$ & $.883^{* *}$ & 1 \\
\cline { 2 - 5 } & Sig. (2-tailed) & .000 & .006 & \\
\cline { 2 - 5 } & $\mathrm{N}$ & 18 & 18 & 18 \\
\cline { 2 - 5 } & & \multicolumn{2}{|l}{}
\end{tabular}

It is evident that the corresponding coefficients between emission and cost performance achieve more than 0.8 in all three scenarios. Regarding emission and schedule performance, the corresponding coefficients can reach to 0.8 as well. In terms of the cost and schedule performance, the coefficients are about 0.6 , except in the scenario of using 2 cranes. Thus, according to the concept of correlation analysis (Tang et al. 2007), the relationship among the three factors demonstrates a high correlation. The better emission performance is not cost intensive; rather, the two performance options display similar trends.

With regards to the schedule: though it does not always match the changing trend of either emissions or cost, schedule is not sacrificed by the improvement of emission performance. The alternatives often have a better integrated performance for low cost, high schedule and low emissions considerations.

Along with modeling different construction operations, the DES methodology can calculate the integrated performance of the cost, schedule and emissions of construction equipment. In this case, the three factors show different performance under the various on-site operation situations, making it possible for decision-makers to choose the desired integrated performance of cost, schedule and emission factors with or without considering the external constrictions.

\section{LIMITATION}

In this paper, only one representative operation of RFC construction is applied as the case study to show the correlation between cost, schedule and emission by simulation. Moreover, when establishing the DES model, we made some assumptions to facilitate the simulation, for example, the breakdown of trucks and cranes are ignored, since our objective is to demonstrate that using DES is effective to evaluate the cost, schedule and emission performance of RFC. Thus, additional research is required to make a more comprehensive analysis on more operations and more combination alternatives of the size of equipment fleet. 
On the other hand, there are some limitations inherited from the selection of carbon emission rates as well, which is mentioned in Ahn and Lee (2013). The carbon emission rates for working and idle modes were determined by some representative data, rather than equipment-specific data. It was mentioned in other studies that the engineer ties affect the fuel consumption, cost and operation efficiency of the equipment. In the future, it is necessary to build a database of fuel use and emission rates that can be expandable to commonly used construction equipment with various engine sizes.

\section{CONCLUSION}

With the increasing application of RFC in dam construction, managers seeking to make better-informed decisions demand a way to evaluate the integrated performance of cost, schedule and emissions. Since RFC is a new construction method, it is necessary to apply the methodology of discrete event simulation (DES) during construction processes to model different dynamic construction operations and to obtain the cost, schedule and emission performance, respectively. This study uses a dam project case to demonstrate the validity of the presented methodology. The establish DES model can almost reflect the real conditions and show the changes of the integrated value. The results show that the cost, schedule and emission performance are highly correlated. Better emission performance does not satisfy the cost and schedule performance. This methodology could help construction managers consider the integrated performance of different options in RFC dam constructions, and target the construction operation that will increase the integrated value, including the cost, schedule and emission performance.

This research has focused on cost, schedule and emission performance in dam construction projects. However, it is known that quality is another important factor in construction management. The results will become more comprehensive and persuasive if this factor is considered in the simulation model as well. Thus, future research endeavors should estimate the quality factor quantitatively based on the on-site monitoring results and input the quantitative value into the established simulation model. Once the quality performance could be obtained along with cost, schedule and emission factors, and the integrated performance (i.e. cost, schedule, quality and emission) would be comprehensively evaluated. It is hoped that our research results will prove that RFC is a potential dam construction method and will encourage the exploration of possible strategies to promote the application of the new method.

\section{ACKNOWLEDGMENTS}

The research and analysis supporting this article was sponsored by National Advanced Technology Research in China (Grant No. 2012AA06A112), State Key Laboratory of Hydroscience and Engineering (Grant Nos. 2012-KY-02, 2013-KY-5), National Natural Science Foundation of China (Grant No. 51079070). Much appreciation should be given to the corporations supports relative data on construction site for this study.

\section{REFERENCES}

AbouRizk, C., 2010. "Role of Simulation in Construction Engineering and Management." Journal of Construction Engineering and Management. 3(7):1140-1153.

AbouRizk, S., and Hajjar, D., 1998. "A framework for applying simulation in the construction industry." Canadian Journal of Civil Engineering. 25(3), 604-617.

Ahn, C., Lee, S., 2013. "Importance of operational efficiency to Construction Operations." Journal of Construction Engineering and Management.139(4):404-413

An, X., et al., 2005. "Experimental study of Self-Compacting Concrete filled pre-packed rock." Concrete, 1, 3-6. (In Chinese)

Bilec, M., Ries, R., Matthews, H. S., 2006. "Life-Cycle Assessment Modeling of Construction Processes for Buildings." Journal of Infrastructure System, 16(3), 199-205. 
Carmichiael., D.G., Williams., E.H., Kaboli., A.S., 2012. "Minimum Operational Emissions in Earthmoving." Construction Research Congress. Purdue University.

EPA. 2008. "Quantifying greenhouse gas emissions in key industrial sectors.” EPA 100-R-08-002, Sector Strategies Division, US EPA, Washington D.C. Accessed May 23, 2013 http://www.epa.gov/sectors/pdf/2008/2008-sector-report-508-full.pdf.

González, V., Echaveguren, T., 2012. "Exploring the environmental modeling of road construction operations using discrete-event simulation." Automation in Construction, 24:100-110

Hendrickson, C., and Horvath, A., 2000. "Resource use and environmental emissions of U. S. construction sectors." Journal of Construction Engineering and Management. 126(1), 38-44.

Halpin, D. W., 1977. "CYCLONE: Method for modeling of job site processes." Journal of the Construction Division. 103(3), 489-499.

Heydarian, A., Golparvar-Fard, M., 2011. "A Visual Monitoring Framework for Integrated Productivity and Carbon Footprint Control of Construction Operations." Proceedings.of the 2011 ASCE International Workshop on Computing in Civil Engineering, Technical Council on Computing and Information Technology of ASCE, Miami, Florida, pp. 504-511.

Huang, M., An, X., Zhou, H. and Jin, F., 2008. "Rock-Fill Concrete, A New Type of Concrete." Proceeding of International fib Symposium2008, The Netherlands, 1047-1049.

Hung, C., Wei, C., Wang, S., Lin, F., 2009. "The study on the carbon dioxide sequestration by applying wooden structure on eco-technological and leisure facilities." Renewable Energy. 34, 18961901.

International commission on large dams (ICOLD), 2012. Role of dam. Accessed July,15 2012. http://www.icold-cigb.org/GB/Dams/Role_of_Dams.asp

Ioannou, P. G. and Martinez, J. C., 1996. "Comparison of Construction Alternatives Using Matched Simulation Experiments." Journal of Construction Engineering and Management. 112(3), 234-241.

Jin, F., and An, X., 2003. "Construction Method of Rock-Filled Concrete Dam." China. (In Chinese)

Jin, F., An, X., Shi, J. and Zhang, C., 2005. "Study on rock-filled concrete dam." Journal of Hydraulic Engineering, 36(11), 1348-1351. (In Chinese)

Keoleian, G. A., Kendall, A., Dettling, J., Smith, V.M., Chandler, R. F., Lepech, M. D., and Li, V. C., 2005. "Life Cycle Modeling of Concrete Bridge Design: Comparison of ECC Link Slabs and Conventional Steel Expansion Joints." Journal of Infrastructure Systems, 11(1), 51-60.

Kuehn, U., 2011. "Integrated Cost and Schedule Control in Project Management." Management Concepts, Incorporated.

Lempérière, F., 2006. "The role of dams in the XXI century." Report for ICOLD'S Commitee on Governance of dams. Hydropower \& Dams Issue 3.

Lewis, P., Leming, M. and Rasdorf, W., 2011. "Impact of Engine Idling on Fuel Use and CO2 Emissions of Nonroad Diesel Construction Equipment." Journal of Management in Engineering. 28(1), 31-38.

Liu, X. L., Wang, H. T., Chen, J., He, Q., Zhang, H., Jiang, R., Chen, X. X., and Hou, P., 2010. “Method and basic model for development of Chinese reference Life cycle database of fundamental industries." Acta Scientiae Circumstantiae, 30(10), 2136-2144.

Löfgren, B., Tillman, A., 2011. "Relating manufacturing system configuration to life-cycle environmental performance: discrete-event simulation supplemented with LCA." Journal of Cleaner Production. 19:2015-2024

Martínez, J. C., 2001. "Methodology for Conducting Discrete-Event Simulation Studies in Construction Engineering and Management." Journal of Construction Engineering and Management. 136(1): 3-16.

Martínez, J. C., 2010. Role of Simulation in Construction Engineering and Management. Journal of Construction Engineering and Management. 3(7):1140-1153. 
Sharrard, A.L., Matthews, H.S., Roth, M., 2007. "Environmental implications of construction site energy use and electricity generation." Journal of Construction Engineering and Management. 133, 846-854.

Shen, L.Y., Vivian W.Y., Tam, L., Ji, Y.B., 2010. "Project feasibility study: the key to successful implementation of sustainable and socially responsible construction management practice." Journal of Cleaner Production. 18:254-259

Tang, P., Cass, D., Mukherjee, A., 2011. "Using schedule simulation approaches to reduce greenhouse gas emissions in highway construction project." Proceedings of the 2011 Winter Simulation Conference.

Tang, W., Clifton, C., Duffield, C. F., 2006. "Partnering Mechanism in construction: An Empirical Study on the Chinese Construction Industry." Journal of Construction Engineering and Management. 3, 217-229.

Wong, J., Li. H., Wang, H., Huang, T., Luo, E., Li, V., 2012. “Toward low-carbon construction processes: the visualization of predicted emission. Automation in Construction.” In Press, Corrected Proof, Available online 17 October 2012

\section{AUTHOR BIOGRAPHIES}

CHUNNA LIU is a Postdoctor in the Department Of Hydraulic Engineering, State Key Laboratory of Hydro Science and Engineering in Tsinghua University. Her research interests include applications of simulation methods to dam projects, evaluation of dam construction methods, construction operation optimization, and the sustainable evaluation of dams. Her email address is liucn08@mails.tsinghua.edu.cn.

XUEHUI AN is a Professor in the Department Of Hydraulic Engineering, State Key Laboratory of Hydro Science and Engineering in Tsinghua University. He received his $\mathrm{PhD}$ in Civil Engineering from Tokyo University in Japan. His research interests include advanced construction technologies, non-linear simulation and analysis of reinforced concrete, the sustainable evaluation of dams. He serves as the editor of the Journal of Computers and Concrete. His email address is anxue@mail.tsinghua.edu.cn.

CHANGBUM R. AHN is an Assistant Professor in Construction Engineering and Management Division in Charles Durham School of Architectural Engineering and Construction at the University of NebraskaLincoln. He received his $\mathrm{PhD}$ in Civil Engineering from the University of Illinois at Urbana-Champaign. His research interests include simulation, environmental impact assessment, and smart sensing. His email address is cahn2@unl.edu.

SANGHYUN LEE is an Assistant Professor in Department of Civil and Environmental Engineering at University of Michigan. He earned a PhD in Construction Management and Information Technology from MIT, and worked at CRA International as a consultant and participated in numerous international construction projects while teaching Project Management at MIT (2006-2007). Dr. Lee's main research interest is the understanding and management of construction dynamics through the design and development of mechanisms, models, and systems that enhance proactive management of mega construction projects. His email address is shdpm@umich.edu. 